\title{
TOURISM AND SCHIZOPHRENIA: AN ITALIAN CASE STUDY
}

\author{
Barbara Galbusera, $\mathrm{PhD}^{1}$
}

DOI: https://doi.org/10.31410/tmt.2018.441

\begin{abstract}
This paper presents a case study that demonstrates how a family enterprise hotel can increase their business accepting clients with schizophrenia. All this is possible through a pedagogical training allowing the hotel staff to focus on the interest of the person and not on his schizophrenia. The outcomes are: the customer can spend positively his holidays far from usual places, it improves in the Italian population a culture of inclusion and it increases the economy not only of the hotel, but also of the country.
\end{abstract}

Keywords: schizophrenia, tourism, pedagogy, training, inclusion, economy

\section{INTRODUCTION}

I 2017 Italy presented a gradual economic recovery (thanks to the reform of the Jobs Act) and this allowed greater participation in the labour market for women. Nevertheless, in this country persists an atmosphere of uncertainty and mistrust caused by variables such as: the weak labour market recovery, the decrease in productivity, the need to consolidate the banking system, tax evasion, presence of geopolitical tensions around the Mediterranean area that slow down the trade with other countries and disorganized separation between the United Kingdom and the European Union. This has encouraged in the Italian people the need to reduce consumptions and increase savings [1]. This situation greatly affects all sectors of the labour market. In this sense, the enterprises (including family enterprises) have to find strategies to improve their profits. According to the OCSE the secret to get out of this impasse is to improve the functioning of the labour market and the educational system: this would allow an increase in the welfare of the citizens and a most encompassing social-economic system [1].

For these considerations, it is appropriate that businesses can use all occasions (even those that are born in the offhand and randomness) to rethink their economies. Small family enterprises that operate in the field of tourism (for example to those who run the hotels) may increase their budgets by creating ad-hoc solutions for not only economic needs of customers. In this regard we intend in this contribution to discuss a case study: how a family-enterprise hotel has allowed a client with schizophrenia to spend positively his holiday.

The choice to describe this experience is motivated by the fact that the work done is an unexplored field.

\section{LITERATURE REVIEW}

From the 1960s onwards in Italy a period of reflection about the care of psychiatric patients has begun. Engine of this change was the psychiatrist Basaglia. He speculates that the person with mental illness can recapture his identity as a person and operation of intentionality, freedom

University of Bergamo, Via Lombardia 74, La Valletta Brianza, Italy 
and responsibility not only through the care or assistance within the main institution, but also with rehabilitation and education interventions. The positive outcomes of the experience of this idea have led the author to claim that these interventions could be carried out in the territory of origin of the patient. Deinstitutionalization movement is born; theoretical-practical paradigm through which develops the so-called "psychiatric territorial" and thanks to that, psychiatric patients with important pathologies could be discharged from asylums [2], [3], [4].

This movement was so disruptive that allowed the perpetrators of other disciplines of study to begin to deal with psychiatry (sociology [5], pedagogy [6], [7]).

Also, the pedagogical studies were involved. Authors of this discipline began to ask themselves some fundamental questions: how to create educational experiences for people with a psychiatric diagnosis? Which are the most suitable didactics? Nowadays it is possible to outline the theoretical and practical path of pedagogues in two distinct views. To the first view belong the authors who argue the importance of creating a special education. It is indicated then the operators know and understand the psychopathological condition of the patient before teaching [7]. To the second view belong those authors whose contributions support the need of personalizing didactics. It is hoped therefore that the professional knows the person as a "whole" and "throughout her/his experience" and, from that, creating to her/his education experiences [8], [9].

It should be noted however, that in view of the social-political transformation produced by the deinstitutionalization culture movement created in Italy [2], [3], from the development of medicine and neuroscience [10], the creation and development of psychiatric drugs in treating mental illness [11] and interventions of education and rehabilitation [12], currently we are still unable to stem in the patient some signs and symptoms that the mental illness brings itself. This is the case of some patients with schizophrenia who live in a still active dimensions, such as visual and auditory hallucinations.

Regarding these symptoms it should be mentioned that, today, there is a tendency in education and psychiatric rehabilitation to teach the patient to recognize and understand his symptoms to identify the warning signs of a crises, communicate to the care giver or operators any inconvenience, knowing how to find useful strategies to ensure that these symptoms do not invalidate the person's life [12]. Among these interventions there is one to teach the patient that there is a private place and private time where the person may, for example, speak with his own voices, and public place and public time in which it is required to the person to stay in relationship with others and not only with himself [13], [14]. Despite the sense of these ideas are understood and shared by the patient sometimes the person is not always able to keep private his own world. It is on these occasions ordinary people can: not knowing how to relate with then, avoid them, spread them apart by themselves, exclude them, feel fear [15], [13], [14].

The times when the person with schizophrenia expresses his emotional world in public spaces also represent the litmus test that the deinstitutionalization process has spread out. On this occasion it can actually consider if there is a real inclusion of the person with schizophrenia.

This deserves a specific reflection on the case of those schizophrenia patients who go on holiday away from the place and usual relationship. In this circumstance it can be detected whether the person with schizophrenia as tourist can experience exclusion or inclusion in the social environment. 
In this discussion we intend to discuss a case study that allows to identify the state of the art about the social inclusion of the person with schizophrenia; on the other hand, a teaching intervention can: facilitate the acceptance of the person in a social context; create an enabling environment that allows the customer a repeat of the experience; leverage the ability to increase the number of customers in the hotel.

\section{MARCO: A CASE STUDY}

Marco is a schizophrenic patient who attends the psychiatric day care. He is fifty years old and lives alone. He is not working, has good autonomy in daily life and has few friends. In August 2017 decides to take a holiday and tell the psychiatric day care that he will travel to the sea for one month. He comes to tourist and look for a hotel who can accommodate him. Locates a family enterprise hotel ${ }^{2}$ with twenty rooms. Agrees with the reception that plans to stay for about four days, he will pay day by day, and take only breakfast. He also asks if there is a possibility to find a job in this hotel or in other shops in the town. The hotel's manager responds to Marco who aren't looking for staff even she is not aware of jobs in the surrounding area. It should be noted that, when she's just looking at the potential client, she would like to inform him that the hotel is full. In fact, she perceives some discomfort during intercourse and hears that Marco may be an annoying customer. Even the physical appearance does not augur in his favor: he is unkempt and smelly. The customer travels with a small old suitcase and an old empty bucket containing the rag for cleaning, a detergent to clean floors and one for the windows cleaning. After the first days at the hotel, all the staff realizes that Marco has some quirks and particular habits. During the breakfast he requires that there is some order on the table and forces the waitresses to perform some rituals before serving breakfast. By mid-morning the client travels in the common areas of the hotel talking to himself out loud. After the first night spent at the hotel, Marco complains to the director because the cleaning service lady, after washing floor of his room, hasn't placed his slippers where he placed the suitcase the day before and changed place to the toothpaste (the same remark he will do in the following days). When it goes up or down the stairs, Marco strips his body near the wall and stops for a few moments on the landing before continuing the walk. Every time he passes by to place of the flowers painting on the landing of the first floor he stops for a few moments and blankly he reflects in it. Every day at two o'clock in the afternoon he goes to the bar, he drinks coffee in a paper cup and tells that he took a rest from the center where he routinely goes throughout the year (he does not specify the institution which he attends), states that he's looking for a job, asks if some shopkeeper has phoned in the hotel to offer him a job. After four days of stay in charge of the hotel, the owner of the hotel begins to worry. At the hotel they get new customers. Marco has decided to extend his holidays and books another four days (keeping the agreement to pay day by day). He continues in his habits, but the most annoying one is his morning soliloquy in the common areas of the hotel. The Hotel manager is torn. She would like to tell him that the hotel is fully booked so that, after the reserved days, he is forced to leave; on the other side she would give him the opportunity to stay. In fact, the economic crisis has considerably reduced the reservations in this year and losing a client means losing money. It should be noted that, during the period when Marco stays at the hotel, the Manager has contacted an expert in special education to assume a specific holidays packages for families whose children have a special education need. This choice was made

The hotel is run by Mrs. L. owner and employee at the hotel reception. The Lady also takes care of phone reservation and, sometimes supports the kitchen. The staff is composed by the cooker (husband of the owner), two cleaning employee (one of that is also employed in the kitchen) and a waiter. The hotel employees work forty hours per week. 
in order to increase the possible customers. In one of these meetings the hotel manager exposes the problem that the staff is having with Marco.

During the meeting with the expert it is addressed the issue of emerging economic crisis. It appears that in recent years the choice of direction has been to accommodate different types of "strange customers" that, in previous years, they would have excluded even if the facility has no reservations. In particular, taking as an example the story of Marco, it underlines the discomfort of having a client who creates difficulties to them and confusion to the other guests. It also points out that the biggest concern is losing regular customers and decrease the number of new reservations that, in this experience, are always clasped on the recommendation of loyal customers. Mrs. L. tells, that in her experience of the manager, is less problematic "to rent the room to ladies of questionable morality who come to Italy for sex tourism, but that doesn't take their customers at all, then rent the room to adults who exhibit behavioral quirks in the common areas of the hotel". For the Manager the latter type of clients can strike more fear to the other guests so much, to force them to change and reduce the bookings.

\section{THE START OF THE PROJECT}

Sharing the experience of the Hotel Manager to the expert of special education has led to the creation of the project that we are submitting.

The preparatory phase of the organization of the project was the collection of narrative through a pedagogical perspective [16], made vis to vis, in an environment chosen by the respondent to identify the needs of the Manager of the hotel. At the end of the interview (which was about an hour) it has been established the goals and the methods of intervention. It has been emerged the need to create a training program ad-hoc for the hotel manager, enabling both to improve the skills in order to manage the situation and to coordinate the activities of her employees (satisfying their curiosity about how it is right to act in respect to requests of Marco). Therefore, the objectives of the intervention were established concerning on the one hand Marco and on the other the operators. As for the customer it would be to identify his specific needs and the sense of his demands so that he could enjoy the holiday in the hotel. As regards the operators it was suggested that the training would have permitted to: exit from impasse that the customer provided through his demands; meet the needs of Marco and respect his role as a hotel guest, contain the moments when other customers of the hotel could feel uncomfortable (especially when Marco spoke out loud alone in a public accessible area of the hotel).

\section{PROJECT VIEW, INSTRUMENTS AND PRODUCTION TIMES}

At the end of the interview, after establishing training objectives, we have set the basis for structuring the intervention. The phases were seven:

1. collection of Marco's needs and staff' by the Manager of the Hotel throughout an ad hoc board created by the trainer (to be carried out before the formation);

2. meeting with the Hotel Manager held by the expert of special education (performed after two days from the interview);

3. meeting between the Hotel Manager and the staff where they share the highlights of the training and revalue questionnaires built before the training; 
4. second training session with the Manager held by the expert of special education (after three days from the first meeting);

5. meeting between Manager and staff to share the outcomes of the second part of the training;

6. after about four weeks, meeting between Manager and staff to assess the points of strength and the points of weakness of the intervention;

7. one month away from the intervention, meeting between the expert in special education and the Manager to collect observations, ideas and reflections about how it has been performed.

In the first phase of the project the Manager has been asked to find a space for dialogue with her employees. It has been created a questionnaire that allows, on the one hand each operator to detect his needs as a worker, and on the other hand the needs of the client. Regarding customer's needs it has been called to detail, including empirical examples, through which customer's needs could be met and which are considered inadequate to the environment by the operator.

During the first training session (second phase) it has been presented theoretical principles to refer during the training. It has been therefore defined theoretic framework of pedagogical use of personalism as reference [8], [9], [17], [18] and integrated functional method constructs presented by Zapparoli [13], [14], [19], [20]. The meeting lasted 90 minutes. At the end the Manager has been asked to share topics with the staff and, by the new information, to reevaluate the job performed in the first phase (review the questionnaire about the needs of the operators and the client). After three days (third phase) it has been carried out a new meeting between the expert of special education and the Manager, where it has been analyzed the case of Marco and evaluated two questionnaires relative to the analysis needs completed by the staff. The Manager have been asked to share the training contents with the staff with the objective to outline a new shared strategy to accommodate the client. After four weeks the Manager have been asked (and the staff) to identify the points of strength and the points of weakness of the intervention. One month away from the training (fourth phase) the meeting between the expert in special education and Manager took place. The duration of the meeting was about ninety minutes. Considering the job experience and the new skills of the Manager and the staff, it has been evaluated if the acquisition of new skills of the staff allowed, on the one hand a greater predisposition to accommodate clients with schizophrenia, and on the other hand favored the possibility of increasing the numbers of reservations.

\section{DATA COLLECTION AND PROCEDURES}

Pre and post intervention data are collected using self-report instrument and interviews. The participants are informed about the purpose of the study. They are also informed that participation is voluntary and anonymous, that data is kept in a safe with only research group has access to, that it is possible to withdraw consent without explanation, that results are reported so that the identity of the participants is protected, and that results are going to be reported at conference and in scientific journal.

\section{DISCUSSION}

The data of this research has been analyzed from the case study [21], [22], [23], [24] and the analysis of the replies to the questionnaire have been conducted. 
Data has been collected from the interview of the Manager together with the staff questionnaires. This study has for this reason some boundaries, as pointed out by Craig et all. [25] and Gourging et all. [26], since randomized control trials are not optimal for assessing complex interventions in everyday clinical practice. The clinical case described above shows that, in the face of a great cultural and political investment on the deinstitutionalization of psychiatric patients and the emergence of therapeutic rehabilitation courses with the aim to include the person in a social context, currently in Italy there are not yet conditions to assert that the person with schizophrenia can be understood and accepted in his needs. Emblematic is the phrase of the Manager found within the pre-intervention in which she declares the preference of the adult with behavioral quirks - customers with little morality. The analysis of the questionnaires completed by the staff and the Manager, before the training, demonstrate the presence of two positions. On the one side there is the position of the Manager that has economic need not to have losses and the need to maintain a social control on what's going on in the hotel. On the other side there is the staff position, answering the questions of the questionnaire from their professional role and from their labour status of subordinate. In their writings they say: the desire to accommodate the customer to satisfy even unnecessary requests, the absence of moral judgements towards the customer, the fear of being taken for non-compliance work in case the operator proves to be unwelcoming towards customers (this last element is not fulfilled by the husband of the Manager; he doesn't feel like he undermined their professional role within the hotel). A single element emerged in the first questionnaire linked the Manager to her employees: the discomfort that they feel when they see and hear about Marco talking loud alone in a public place. This stirs feelings of helplessness and fear in all of them.

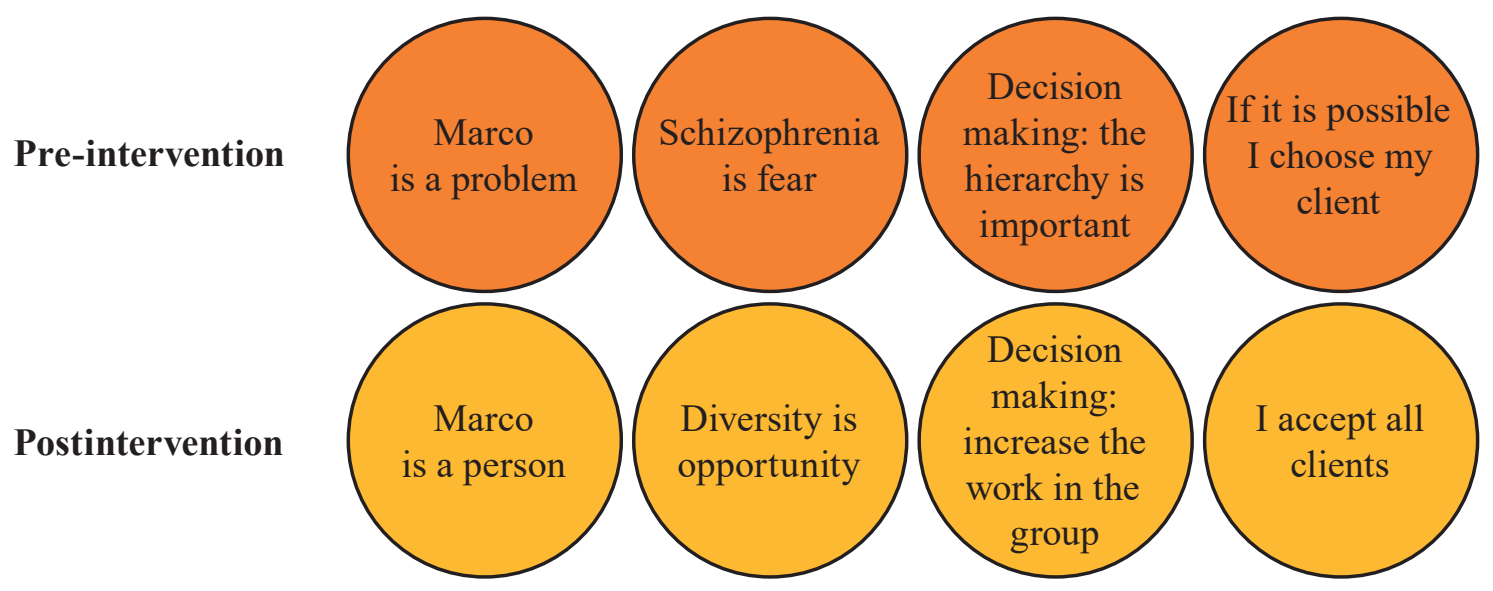

Figure 1: Change of the perspective

The analysis of the data obtained in the second tab shows that, after the training, considering the new skills acquired, Manager and staff cooperate more in sharing information. The size of the working group integrates itself to best meet the needs of Marco and try to contain his soliloquies in public place. This new element also allows a change in perception of staff: it disappears into the single operator the fear of being rebuked for default. In addition, the Manager's questionnaire, disappears the belief that she must be the only one guarantor of the security of the hotel. Instead, it emerges the idea that they can ensure the safety of hotel guests through a team effort. In the second questionnaire remains the economic need not to have heavy losses. Manager argues also that the training allowed her to understand and get to know the person with schizophrenia and this reduced her distrust to Marco. She also considers that it might be less suspicious to prospective clients that have behavioral quirks. 
From the analysis of data collected during the collection of narrative made with the Manager, for a month after of training, it appears that the training allows in all hotel operators (including Manager): greater attention to the observation of the customer's behaviour, especially towards those who show behavioral oddities; the perception of belonging to a group that is able to find the strength to build correct strategies to accommodate more clients. In the analysis of narrative, it is also noted that in some staff members there is a desire to be supported by the special education expert in case of a need, and if there are (in the hotel) customers with complex needs to be managed, that can create relational problems between colleagues.

\section{CONCLUSIONS}

Despite its limitation, this study clearly supports the importance of information and training for operators who work in the tourism industry. Data analysis shows that the skills acquired by operators through this training allow not only to provide more of the same to welcome the guest (even with behavioral quirks), but even a greater sensitivity to the diversity of the person. It should be noted that the staff involved in the study, helped to recognize certain signs and symptoms of schizophrenia and to prepare and receive the needs of the person living with schizophrenia, but the theoretical framework of reference that guided the training (the pedagogy of personalism) allowed operators to acquire a new glimpse into the diversity of each human being. In this sense, and this is demonstrated by the data in the second questionnaire, the reflection that each member of the staff has on customer's needs and his own actions arises not thinking about the specific pathology of the guest, but considering the person standing in front of. In this study, a positive function is the experience they have acquired to recognize the needs of the person and to consider his diversity: the diversity of the other becomes the driving force behind the refection and change. Considering the analysis carried out in this study, it has been shown that that this atmosphere of curiosity about other, prepares the staff and the management to a greater acceptance of all customers while avoiding the selection of the guests to whom they may perceive distrust: this may improve the social inclusion of people; create an enabling environment that allows customers to repeat the experience; develop positive circuit (quoted by the Manager in the case that has just been described), which allows the customer to recommend the hotel to any friend, thus it could increase the number of reservations.

\section{LIMITATIONS AND FUTURE PROJECT}

This study has an important limitation, because it has no randomized control trials. Therefore, this kind of study is not adequate to interventional education.

It should be noted that this research (that is still unexplored field in Italy) shows how it can be viable and profitable to introduce a clinical-pedagogy perspective for future research for the tourism industry. For this reason, it would be important to increase the number of case studies with the aim of demonstrating that described pedagogical paradigm could increase hotel business by accepting clients with schizophrenia.

In addition, it would be also interesting to evaluate if this training could: be really a device that enables greater inclusion of any person in a social contest; detect if it encourages group dynamics where each operator feels as active part of a shared project; boost tourism even for those people whose changing habits and environment are more complex. 


\section{REFERENCES}

[1] OCSE, 2017, Rapporto economico OCSE Italia, Febbraio.

[2] Basaglia, F. 2014 L'utopia della realtà, Fabbri Publishing, Milano.

[3] Basaglia, F. (Ed.) 1968 L'istituzione negata, Einaudi, Torino.

[4] Basaglia, F. 2000 Conferenze brasiliane, Raffaello Cortina Editore, Milano.

[5] Donaldson, E.J. (Ed.) 2018 Literatures of Madness. Disability Studies and Mental Health, Palgrave Macmillan, Cham, Switzerland.

[6] Chiosso, G. 2012 Novecento pedagogico, La Scuola, Brescia.

[7] Crispiani, P. (Ed.) 2016 Storia della Pedagogia speciale. L'origine, lo sviluppo, la differenziazione, Edizioni ETS, Pisa.

[8] Bertagna, G. 2010 Lo "speciale” della Pedagogia Generale, in L. D’alonzo, G. Mari, (Eds.), Identità e diversità nell'orizzonte educativo. Studi in onore di Giuseppe Vico, Vita e Pensiero, Milano, pp. 51-65.

[9] Bertagna, G. 2006 Pedagogia dell'«uomo» e pedagogia della «persona umana»: il senso di una differenza, in G. Bertagna, (Ed.), Scienze della persona: perché? Rubbettino, Soveria Mannelli, pp. 17-74.

[10] Vicari, S., Caselli, M.C. (Eds.) 2010 Neuropsicologia dello sviluppo. Normalità e patologia, Il Mulino, Bologna.

[11] Zoli, S. 1993 E liberaci dal male oscuro, Longanesi \& C, Milano.

[12] Carrozza, P. 2012 Principi di riabilitazione psichiatrica: per un sistema di servizi orientato alla guarigione, FrancoAngeli, Milano.

[13] Zapparoli, G.C. 2009 Introduzione al modello dell'integrazione funzionale nella patologia grave, Dialogos, Milano.

[14] Zapparoli, G.C. 1999 La psicosi e il segreto, Bollati Boringhieri, Torino.

[15] Zapparoli, G.C. 2002 La follia e l'intermediario, Dialogos, Milano.

[16] Galbusera, B. 2017 Pedagogia e autismo: per una formazione degli operatori alla didattica scolastica, tesi di dottorato non pubblicata, Università di Bergamo, Bergamo.

[17] Bertagna, G. 2010 Dall'educazione alla pedagogia. Avvio al lessico pedagogico e alla teoria dell'educazione, La Scuola, Brescia.

[18] Bertagna, G. 2015 L'esperienza umana e educativa tra scientiae e pedagogia. Riflessioni epistemologiche, in D. Generali, (Ed.), Le radici della razionalità critica: saperi, pratiche, teleologie. Studi offerti a Fabio Minazzi, volume II, Mimesis, Milano, pp. 827-854.

[19] Gnocchi, E., Memmi, V., Tacchini, M., 1993 Nuovi modelli di intervento dell'infermiere psichiatrico, Bollati Boringhieri, Torino.

[20] Tacchini, M.A. (1998) Professione infermiere nei servizi psichiatrici. Dalla teoria alla prassi, Masson, Milano.

[21] Cian, D.O. 1977 Metodologia della ricerca pedagogica, La Scuola, Brescia.

[22] Freud, S. 2014 Casi clinici, Fabbri Publishing, Milano.

[23] Sacks, O. 2011 L'uomo che scambiò sua moglie per un cappello, [1985], Adelphi, Milano.

[24] Yin, R.K. 2005 Lo studio di caso nella ricerca scientifica, Armando Editore, Roma.

[25] Craig, P., Dieppe, P., Macintyre, S., Michie, S., Nazareth, I., Petticrew, M. 2008 Developing and evaluating complex interventions: the new Medical Research Council Guidance, BMJ, https: //doi.org/10.1136/bmj.a1655

[26] Goulding, A., Allerby, K., Ali, L., Gremy, A., Waern M. 2018 Study protocol design and evaluation of a hospital-based multi-professional educational intervention: Persona-Centered Psychosis Care (PCPC), BMC Psychiatry, 18:2699. 